\title{
Daucus carota as a novel model to evaluate the effect of light on carotenogenic gene expression
}

\author{
CLAUDIA STANGE, PAULINA FUENTES, MICHAEL HANDFORD and \\ LORENA PIZARRO
}

Laboratorio de Biología Molecular Vegetal, Facultad de Ciencias, Universidad de Chile, Chile

\begin{abstract}
Carotenoids are synthesized in prokaryotic and eukaryotic organisms. In plants and algae, these lipophilic molecules possess antioxidant properties acting as reactive oxygen species scavengers and exert functional roles in hormone synthesis, photosynthesis, photomorphogenesis and in photoprotection. During the past decade almost all carotenogenic genes have been identified as a result of molecular, genetic and biochemical approaches utilizing Arabidopsis thaliana as the model system. Studies carried out in leaves and fruits of $A$. thaliana and tomato determined that light regulates carotenoid biosynthesis preferentially through the modulation of carotenogenic gene transcription. In this work we showed for the first time that light induces accumulation of psy1, pds and zds2 transcripts in leaves of Daucus carota (carrot), a novel plant model. In addition, modified roots of carrots exposed to light accumulate $\mathrm{zds} 1$, whereas the pds gene is highly repressed, suggesting that some carotenogenic genes, which are expressed in roots, are regulated by light. Additionally, light negatively regulates the development of the modified carrot root in a reversible manner. Therefore, this suggests that light affects normal growth and carotenogenic gene expression in the modified root of carrot plants. The molecular insight gained into the light-regulated expression of carotenoid genes in this and other model systems will facilitate our understanding of the regulation of carotenoid biosynthesis to improve the prospects for the metabolic engineering of carotenoid production in plants.
\end{abstract}

Key terms: carotenoid biosynthesis, carrot, gene expression, light regulation.

\section{INTRODUCTION}

Carotenoids are lipid-soluble molecules of 40 carbons that are synthesized in a wide variety of photosynthetic and non photosynthetic organisms including plants, algae, some fungi and bacteria but not animals. In plants and algae, carotenoids are synthesized in the plastids, such as chloroplasts and chromoplasts. In chloroplasts, these pigments are localized and accumulate in the thylakoid membranes (Cunningham and Gantt, 1998), acting as accessory pigments in the Light Harvesting Complex (LHC), during photosynthesis (Britton, 1995). Carotenoids are also synthesized and accumulated in lipid bodies or in crystalline structures inside chromoplasts, plastids that accumulate pigments in flowers, fruits and reserve or modifies roots (Vishnevetsky et al., 1999). In flowers and fruits, the presence of these pigmented molecules serves to attract pollinators and seed dispersal agents by the intense yellow, orange and red colors that they provide to these organs (Grotewold, 2006).

In addition, carotenoids are precursors for the biosynthesis of the plant hormone abscisic acid (Crozier et al., 2000), protect plant cells from photo-oxidative damage by quenching singlet oxygen produced from chlorophyll triplet in the reaction center of photosystem II (Takano et al., 2005; Telfer, 2005) and exert a photoprotective role during excessive light incidence through thermal dissipation by means of the xanthophyll cycle, protecting the plant from photo-oxidative damage. 
Carotenoids are not synthesized by animals. Therefore, they must be ingested in the diet for the subsequent synthesis of related molecules such as vitamin A, retinal and retinoic acid, which play essential roles in nutrition, vision and cellular differentiation, respectively (Krinsky et al., 1994). Furthermore, these molecules have also been shown to delay the aging process due to their antioxidant properties (Mordi, 1993; Bartley and Scolnik, 1995). At the same time, oxidative damage associated with several pathologies, including aging (Esterbauer et al., 1992), carcinogenesis (Breimer, 1990) and degenerative processes in humans, among others, can be resisted by ingestion of carotenoids (Snodderly, 1995; Mayne, 1996, Rao and Rao, 2007). Birds, fish and crustaceans utilize carotenoids for pigmentation and nutritional purposes. For example, the cetocarotenoid astaxanthin is responsible for the orange color of salmon meat and lobster shells (reviewed in Grotewold, 2006). Carotenoids also have agronomic and commercial importance in several ornamental plants, in the cosmetic and food industries (Klaui and Bauernfeind, 1981) and are employed as poultry and fish feed additives (reviewed in Bjerkeng, 2000).

Until the sixties, research in this area had been centered on the biosynthetic route of carotenoids (Cunningham and Gantt, 1998). Subsequently, almost all genes termed carotenogenic genes that codify for enzymes involved in the metabolism of carotenoids in diverse plant species, algae, fungi and bacteria have been identified and characterized (Hirschberg et al., 1997; Cunningham and Gantt 1998; Cunningham, 2002; Naik et al., 2003; Lodato et al., 2004).

In plants, carotenogenic genes are encoded in the nuclear genome and the synthesized proteins are targeted as preproteins to the plastids, where they are post-translationally processed. Carotenoid biosynthesis in chloroplasts begins with the synthesis of the isoprenoid isopentenyl pyrophosphate (IPP; Fig. 1), through the non-mevalonate route (Schwender et al., 1996; Lichtenthaler et al., 1997), by condensing D-glyceraldehyde 3-phosphate with pyruvate, forming 1-deoxy-Dxylulose-5-phosphate (DOXP) (Shanker et al., 2003; Rohmer, 1999), a reaction catalyzed by DOXP-synthase (DXS). In subsequent steps and catalyzed by DOXP reductoisomerase

(DXR), hydroxymethylbutenyl diphosphate (HBMPP) synthase (HDS) and HBMPP reductase (HDR), DOXP is transformed into IPP (Lichtenthaler, 1999). IPP molecules synthesized in the plastids are then isomerized to the allylic isomer, dimethylallyl pyrophosphate (DMAPP) by means of IPP isomerase (IPI). Subsequently, DMAPP condenses with three molecules of IPP to generate a molecule of 20 carbons named geranylgeranyl pyrophosphate (GGPP), in a process involving GGPP synthase (GGPPS). The formation of the symmetrical 40-carbon phytoene from two molecules of GGPP is catalyzed by phytoene synthase (PSY) in a two-step reaction. Phytoene biosynthesis is the first reaction specifically related to the carotenoid biosynthesis pathway. The biosynthesis of carotenoids continues with the desaturation of the colorless phytoene to produce the pink-colored trans-lycopene (Fig.1). These reactions are catalyzed by phytoene desaturase (PDS), forming $\zeta$ carotene, $\zeta$-carotene desaturase (ZDS), which synthesizes pro-lycopene (7, 9, 9', 7'-tetra-cis-lycopene) and carotene isomerase (CRTISO), which transforms pro-lycopene into lycopene (all-translycopene) in plants (Isaacson et al., 2002; Park et al., 2002). In leaves, the activity of CRTISO is substituted by light that photoisomerizes $\zeta$-carotene, neurosporene, and prolycopene (Isaacson et al., 2002). Subsequently, lycopene is transformed into different bicyclic molecules. It has been observed that in plants and algae two enzymes participate in the cyclization of lycopene (Cunningham et al., 1996; Cunningham et al., 2007), lycopene- $\beta$ cyclase (LCYB), which converts lycopene into $\gamma$-carotene and subsequently to $\beta$ carotene and lycopene- $\varepsilon$-cyclase (LCYE) that cyclizes one end of the lycopene molecule with an $\varepsilon$-ring ( $\delta$-carotene), whereas the other ring is formed by LCYB, 


\section{D-glyceraldehyde 3-phosphate}
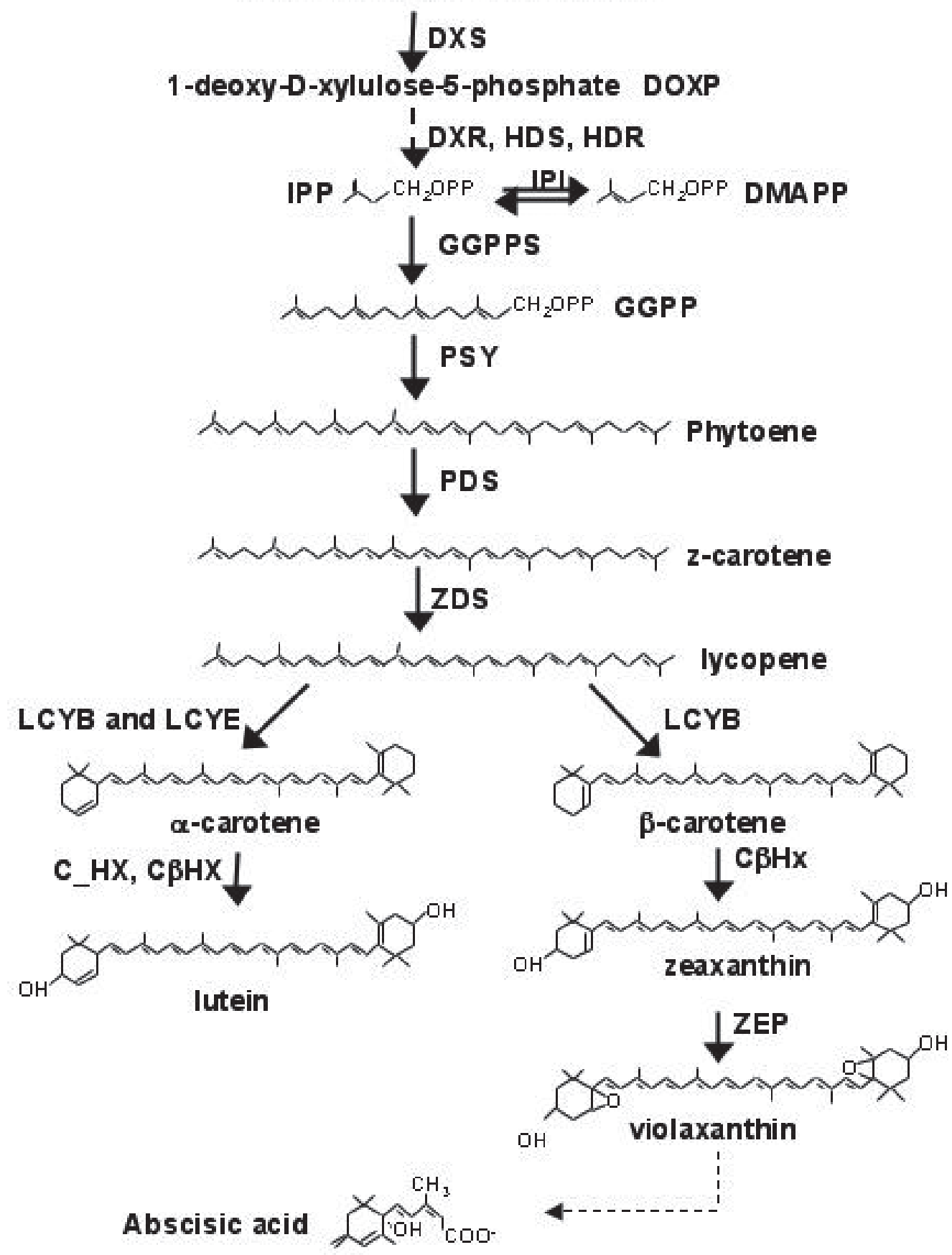

Figure 1: Schematic representation of carotenoid synthesis in plants. The isopentenyl pyrophosphate (IPP) is synthesized in plastids through the non-mevalonate route, and begins with the synthesis of DOXP catalyzed by DOXP synthase (DXS). The other enzymes that participate in the biosynthesis of carotenoids and abscisic acid are: isopentenyl pyrophosphate synthase (IPI), geranylgeranyl pyrophosphate synthase (GGPPS), phytoene synthase (PSY), phytoene desaturase (PDS), z-carotene desaturase (ZDS), carotene isomerase (CRTISO), lycopene $\varepsilon$ cyclase (LCYE), lycopene $\beta$ cyclase (LCYB), $\beta$-carotene hydroxylase $(\mathrm{C} \beta \mathrm{Hx}), \varepsilon$-carotene hydroxylase $(\mathrm{C} \varepsilon \mathrm{Hx})$ and zeaxanthin epoxidase (ZEP). The name and structure of the synthesized carotenes and xanthophylls are included. 
thus producing $\alpha$-carotene (Cunningham et al., 1996). The $\beta$-carotene synthesized is utilized as substrate for the enzyme $\beta$ carotene hydroxylase $(\mathrm{C} \beta \mathrm{Hx})$ to produce zeaxanthin, while the hydroxylation of $\alpha$ carotene by the $\varepsilon$-carotene hydroxylase $(\mathrm{C} \varepsilon \mathrm{Hx})$ and $\mathrm{C} \beta \mathrm{Hx}$ results in the formation of lutein. Finally, abscisic acid is synthesized in the cytoplasm via a series of reactions subsequent to the epoxidation of zeaxanthin by zeaxanthin epoxidase (ZEP) (Cunningham and Gantt, 1998; Cunningham, 2002; Naik et al., 2003).

The regulation of carotenoid biosynthesis has been studied in photosynthetic organs (leaves) and in nonphotosynthetic organs (fruits, flowers, tubers and seeds) of traditional plant models, such as Arabidopsis thaliana, Nicotiana tabacum (tobacco) and Solanum lycopersicon (tomato) (Römer and Fraser, 2005; Howitt and Pogson, 2006). Almost all of these studies show that carotenogenic genes are expressed in photosynthetic organs exposed to different light qualities, during the transition of etioplasts to chloroplasts (de-etiolation) (Römer and Fraser, 2005; Bramley, 2002). During these processes, carotenogenic gene expression is mostly regulated at the transcriptional level mediated by photoreceptors, such as the family of phytochromes (PHYA-PHYE), cryptochromes (CRY) and phototropins (Simkin et al., 2003; Woitsch and Römer, 2003; Briggs and Olney, 2001; Scheppens et al., 2004, Franklin et al., 2005; Briggs et al., 2007).

Light also affects carotenoid biosynthesis in a number of species during fruit ripening and flower development (Zhu et al., 2002, 2003; Giovanonni, 2004; Phillips et al., 2004; Kishimoto and Ohmiya, 2006). During tomato fruit ripening, expression of $\mathrm{dxs}$, hdr, pds and psy 1 is co-ordinately upregulated, whilst at the same time the expression of lyc $\beta$ and lcye decreases (Fraser et al., 1994; Pecker et al., 1996; Ronen et al., 1999; Lois et al., 2000; Botella-Pavía et al., 2004), leading to an accumulation of lycopene in chromoplasts of ripe fruits (Pecker et al., 1996). The psy gene is upregulated during fruit development and ripening (Fraser et al., 1999, Giuliano et al., 1993) and during flower development (Zhu et al., 2002, Zhu et al., 2003). In tomato, two distantly related genes, psy1 and psy2, code for phytoene synthase, and the former was found to be transcriptionally activated only in petals and in ripening of tomato fruits (Welsch et al., 2000; Giorio et al., 2008). Psy2 is expressed in all plant organs, preferentially in tomato leaves and petals (Giorio et al., 2008), but in green or ripe fruits it is only expressed at low levels (Bartley and Scolnik, 1993; Giorio et al., 2008).

Carotenogenic genes are not only expressed in leaves and fruits. In potato, $\beta$ carotene and lutein are synthesized (Nesterenko and Sink, 2003) whilst carotenoids are also present in amyloplasts of cereal seeds such as maize and wheat (Panfili et al., 2004, see Howitt and Pogson 2006 for review). Both potatoes and cereals accumulate low levels of carotenoids in the dark (Nesterenko and Sink, 2003), in contrast to the highly pigmented modified root of carrots.

Daucus carota L. (carrot, $2 \mathrm{n}=18$ ) is a biennal plant whose orange reserve or modified root is consumed worldwide due to its high levels of $\alpha$-carotene and $\beta$ carotene $(8 \mathrm{mg} / \mathrm{g}$ dry weight, Fraser, 2004). The carotenoid composition of a typical orange colored carrot contains predominantly $\beta$-carotene $(45-80 \%)$ and $\alpha$ carotene that together constitute up to $95 \%$ of total carotenoids (Simon and Wolf 1987; Baranska et al., 2006). The major physiological function of the carrot root is as a reserve of assimilates for the production of a flowering stem after appropriate stimuli (Hole 1996). Young carrot roots are pale and start to accumulate carotenoids after the first month of growth, levels of which usually peak after three months, shortly before secondary growth is completed (Suslow et al., 1999).

The complete cDNA sequences of some carrot carotenogenic genes, such as isopentenyl pyrophosphate isomerase (ipi, DQ192183), phytoene synthase 1 and 2 (psy1, DQ192186; psy2 DQ192187), z-carotene desaturase 1 and 2 (zds1, 
DQ222430; zds2, DQ192189), phytoene desaturase (pds, DQ222429), lycopene $\beta$ cyclase (lcyb, DQ192190), lycopene $\varepsilon$ cyclase (lyce, DQ192192) and capsantine capsorubine synthase (ccs: DQ192191), were annotated recently at the NCBI database (Just et al. 2007). The kinetics of the transcript accumulation of some of these genes correlates to total carotenoid composition during the development of modified roots grown in the dark (Clotault et al., 2008). However, to date, the influence of light on carotenoid gene expression in the leaves and modified root of carrots has not been examined. In this report, we show that this environmental factor differentially affects the accumulation of transcripts of several carotenoid genes and alters the morphology and development of modified roots grown in the presence or absence of light.

\section{MATERIALS AND METHODS}

\section{Plant Material}

Seeds of commercially-acquired carrot (Daucus carota L.) cultivar "Nantaise improved 3" were sown hydroponically and cultivated for 4,8 and 12 weeks with a $16 \mathrm{~h}$ photoperiod illuminated with white fluorescent light $\left(450 \mu \mathrm{mol} \mathrm{m} \mathrm{m}^{-2} \mathrm{~s}^{-1}\right)$ at 20 $23^{\circ} \mathrm{C}$. Leaves and modified roots of $12-$ week-old carrot plantlets were harvested and utilized in real time RT-PCR analysis. For light treatments of carrot roots, the upper segment was exposed to white fluorescent light $\left(450 \mu \mathrm{mol} \mathrm{m} \mathrm{m}^{-2} \mathrm{~s}^{-1}\right.$ in a $16 \mathrm{~h}$ photoperiod) for 12 weeks, leaving the lower segment to grow in darkness. The sampled roots are depicted in Fig. 2 and 4. For dark treatment of carrot leaves, leaves of 12-week-old carrot plants were protected from light for $48 \mathrm{~h}$ with aluminium paper to reduce the light level to $0,06 \mu \mathrm{mol} \mathrm{m} \mathrm{m}^{-2} \mathrm{~s}^{-1}$. Leaves and modified root pieces subjected to light and dark treatment from three carrot plants were pooled, frozen in liquid nitrogen, and powdered to isolate total RNA. Each experiment was performed in triplicate.
Reverse transcription and quantitative $R T$ PCR

Total RNA was extracted from frozen powder using RNAsolv (Omega Biotec, USA). Genomic DNA traces were eliminated by a 20 min RNase-free DNase I treatment at $37{ }^{\circ} \mathrm{C}$ followed by addition of $25 \mathrm{mM}$ EDTA-DEPC and incubation at $75^{\circ} \mathrm{C}$ for 5 min to inactivate the enzyme. For cDNA synthesis, $1 \mu \mathrm{g}$ of DNA-free RNA was incubated at $70^{\circ} \mathrm{C}$ for 5 min with $1 \mathrm{mM}$ of oligo dT, then cooled for $5 \mathrm{~min}$ on ice. Four $\mu$ l of Impron II $5 \mathrm{x}$ buffer, $0.5 \mathrm{mM}$ each dNTP, 20U of RNase Inhibitor, and 1 $\mu l$ of Impron II reverse transcriptase (Promega) were added to the RNAs, which were then incubated at $25{ }^{\circ} \mathrm{C}$ for $5 \mathrm{~min}$ and at $42{ }^{\circ} \mathrm{C}$ for $60 \mathrm{~min}$. To inactivate reverse transcriptase, the reaction was incubated at $70{ }^{\circ} \mathrm{C}$ for $15 \mathrm{~min}$. The cDNA was then ready for real time $\mathrm{RT}$-PCR, which was performed with the LightCycler system (Stratagene), using SYBR Green I double strand DNA binding dye. Specific primers targeting carotenoid biosynthesis genes (psy1, psy2, pds, zds1 and zds2; Table 1) were designed from the 5' UTR of each gene on the basis of published cDNA sequences (Just et al., 2007). Specific primers were also designed to amplify ubiquitin, the housekeeping gene used as the reference gene. The absence of amplification from genomic DNA in cDNA samples was tested by comparison of PCR products obtained from cDNA and from RNA templates to ubiquitin primers. These analyses confirmed the absence of genomic DNA in all cDNA samples. The amplification of the fragments was carried out in a total volume of $25 \mu$ l containing $140 \mathrm{nM}$ of the sense and anti-sense primers, $12.5 \mu$ B Brillant SYBR ${ }^{\circledR}$ Green ${ }^{\circledR}$ QPCR Master Mix (Stratagene), $0.375 \mu \mathrm{ROX}$ and $2 \mu l$ of cDNA, prepared as described above. The following cycling conditions were chosen: melting of the cDNA at $95{ }^{\circ} \mathrm{C}$ for 8 min, amplification with 40 cycles with a denaturation step at $94{ }^{\circ} \mathrm{C}$ for $30 \mathrm{~s}$, annealing at $52{ }^{\circ} \mathrm{C}$ for $40 \mathrm{~s}$, and a final elongation at $72{ }^{\circ} \mathrm{C}$ for $30 \mathrm{~s}$. A reamplifying step at the end of the process was also included: $94^{\circ} \mathrm{C}$ for $30 \mathrm{~s}, 50^{\circ} \mathrm{C}$ for $30 \mathrm{~s}$ and 
$72^{\circ} \mathrm{C}$ for $30 \mathrm{~s}$. Fluorescence data was collected after each extension step. Fluorescence was analyzed using LightCycler Analysis Software. The crossing point for each reaction was determined using the Second Derivative Maximum algorithm and manual baseline adjustment. Gene expression levels were calibrated to the average value of organs analyzed to obtain a Calibrated $\Delta \mathrm{Ct}$ for each gene. Amplification efficiency was determined for each set of primers by amplification of the target from a PCR dilution series and according to the equation:

$$
\left(E=\left[10^{(-1 / \text { slope })}\right]-1\right)
$$

The value obtained in this equation was used to obtain the ratio between the carotenogenic gene and the ubiquitin gene expression using the following equation (Pfaffl 2001):

$$
\text { ratio }=\frac{(E \text { carot })}{(\text { E ubiq })} \Delta \mathrm{CP} \text { carot (Ct ubiq-Ct sample carot) }
$$

Efficiency values for carotenogenic genes and ubiquitin amplification during the standard curve calibration were between 0.75 and 0.96 , and $\mathrm{r} 2$ values for these curves were over $90 \%$. Ct values for ubiquitin varied by no more than 2 units among all samples analyzed for each real time experiment. Each qRT-PCR reaction was performed with three biological replicates and each sample was analyzed in duplicate (technical replicate). In all cases, the reaction specificities were tested with melt gradient dissociation curves and electrophoresis gels. To test for significant differences in gene expression, T-test $95 \%$ were carried out using the General LinearModels option in the statistical software package Graphpad Prism. Two tailed Student t-test, $\mathrm{p}<0.05$ (confidence interval 95\%) was used.

\section{RESULTS}

Effect of light on carotenogenic gene expression in leaves of carrots

To evaluate the effect of light in photosynthetic organs, carotenogenic gene expression levels were compared in leaves of

TABLE 1

Primers used for real time RT- PCR analysis of carotenogenic genes expression in D. carota

\begin{tabular}{lllllc}
\hline Primer & Gene & $\begin{array}{l}\text { Accession } \\
\text { number }\end{array}$ & Sequence (5'-3') & Tm $\left({ }^{\circ} \mathrm{C}\right)$ & $\begin{array}{c}\text { Fragment } \\
\text { length (bp) }\end{array}$ \\
\hline zds1F & zds1 & DQ222430 & GAATTCCTCGAATCGGACGGC & 66 & 144 \\
zds1R & zds1 & DQ222430 & CTCGACGCTTGGCCTACTAAT & 64 & \\
zds2F & zds2 & DQ192189 & ACCGGATCAGAATTCCTCGAAT & 62 & 100 \\
zds2R & zds2 & DQ222430 & TTCTCGTGGTTCAATACAATTATACAATG & 76 & \\
pdsF & pds & DQ222429 & TCTCCACCTCCTTCATTCAGTCTAA & 62 & 95 \\
pdsR & pds & DQ222429 & GCAAAATGAAGTCGCTATGTGTCT & 70 & \\
psy1F & psy1 & DQ192186 & AGTCGATGGAGCATTACCATAATTC & 70 & 95 \\
psy1R & psy1 & DQ192186 & CTAATGGGTTACAGAGGGTTGTGTTA & 74 & \\
psy2F & psy2 & DQ192187 & GTTCTTAGCTAAACTTCCGTGGG & 74 & 110 \\
psy2R & psy2 & DQ192187 & GCTGGAGTTAGTGCTACCC & 60 & \\
ubiF & ubiquitin & U68751 & GCTCGAGGACGGCAGAAC & 60 & 121 \\
ubiR & ubiquitin & U68751 & CTTGGGCTTGGTGTAGGTCTTC & 68 & \\
\hline
\end{tabular}


12-week old plants, grown in a diurnal light regime harvested in the light period, with leaves of the same plant subjected to darkness for 2 days. Transcript levels of pds and zds2 were significantly higher in lighttreated $D$. carota leaves compared to those maintained in darkness (Fig 2). This result is in agreement with the relative expression analysis of carotenogenic genes performed in A. thaliana (von Lintig et al., 1997; Welsch et al., 2000, Botella-Pavía et al., 2004). Psy 1 codifies for phytoene synthase, which is involved in the synthesis of phytoene, the branch point for carotenoid biosynthesis. D. carota harbors two genes that are proposed to codify for PSY, psy1 and psy2, which share $73 \%$ identity at their cDNA sequences. We observed that psy1 transcript levels increased five-fold during light treatments, while psy2 was not affected by the same conditions. Pds and zds 2 genes are involved in lycopene biosynthesis and transcript levels of these genes were eleven- and four-fold greater in leaves exposed to light compared to dark-treated leaves, respectively. To date, two sequences (zds1 and zds2), sharing $87 \%$ identity, have been annotated in carrot as coding for $\mathrm{z}$-carotene desaturase. In addition, no other plant species has more than one $\mathrm{zds}$ gene (Cunningham and Gantt, 1998; Naik et al., 2003). Therefore, their role and relative participation in carotenoid biosynthesis under different conditions and throughout development has yet to be analyzed. We observed that zds 2 expression is activated by light treatments, while zds1 transcript accumulation is repressed by light (Fig 2).

\section{Effect of light on modified root development and carotenogenic gene expression}

D. carota has a large reserve root that develops in darkness and where high levels of $\alpha$ and $\beta$-carotene accumulate (Fraser and Bramley, 2004). We studied the effect of

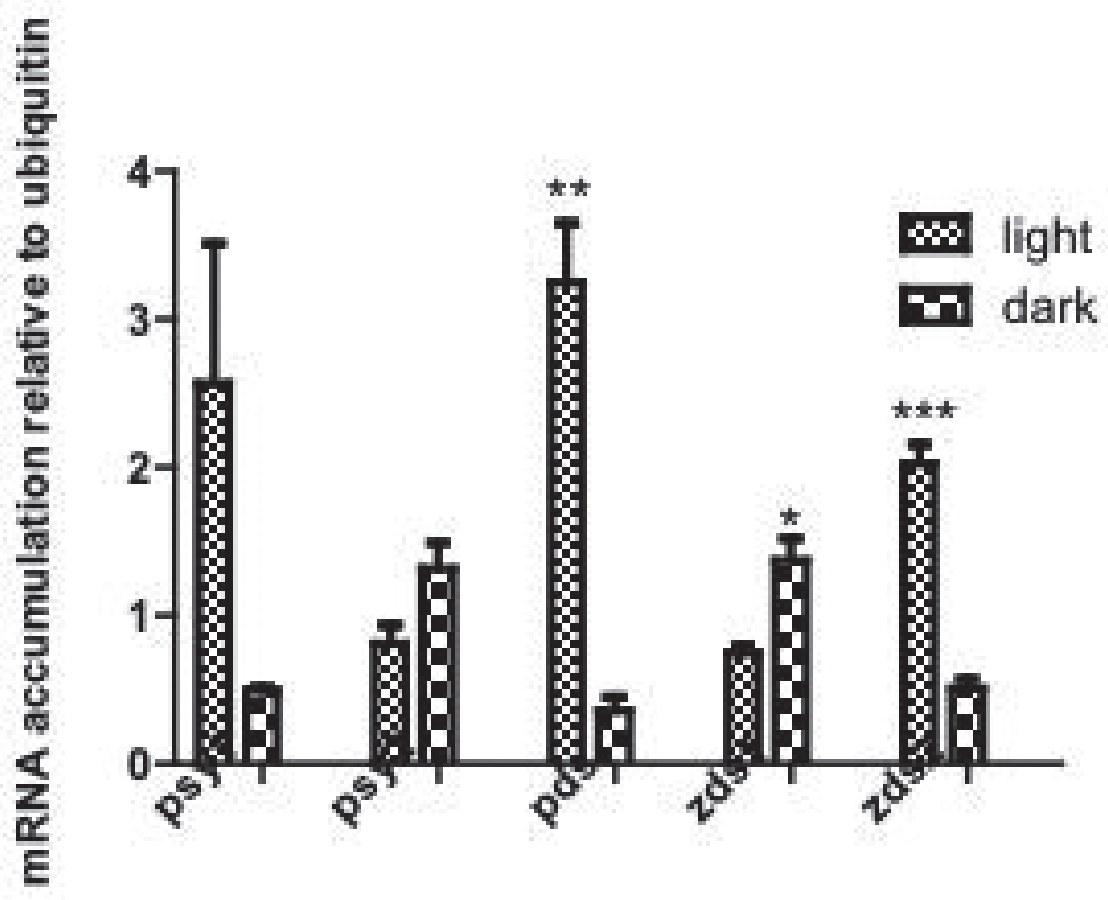

Figure 2: Carotenogenic gene accumulation in leaves of $D$. carota exposed to light or dark conditions. Real time RT-PCR analysis of psy1, psy2, pds, zds1 and zds2 genes during light or dark treatment of leaves in a 12 week- old D. carota plant. Results were normalized with ubiquitin and calibrated against the average of each gene's expression for both conditions. Standard deviations (SD) are the result of three independent replicates. Asterisks indicate significant differences in gene expression among treatments. Student t-test, $\mathrm{p}<0.05$. 
light on the development of the modified root of carrot. As shown in figure 3, a 4week-old carrot plant can be segmented into three sections: leaves $(\mathrm{L})$, roots $(\mathrm{R})$ and a root that will become the modified root of the plant (Fig 3A, Rd). When the upper part of the future modified root was exposed to light $(\mathrm{Rl})$, and the lower part ( $\mathrm{Rd})$ kept in darkness for 8 weeks, only the latter developed into a normal, expanded orange carrot (Fig 3B). However, when the Rl segment was later protected from light (Rld) for a further 4 weeks, this segment developed as a normal modified root (Fig 3C Rl-d and Rd), becoming indistinguishable from the portion of the root grown in continuous darkness (not shown). Therefore, the D. carota modified root develops only in darkness (Rd) and light treatments (Rl) inhibit normal development in a reversible manner (Rl-d).

In order to determine the effect of light on carotenogenic gene expression during modified root development, the relative abundance of some carotenogenic genes in roots exposed to light ( $\mathrm{Rl}$ ) and in modified roots grown in normal development conditions (Rd) from a 12-week-old carrot plant was measured by real time RT-PCR (Fig.4).
Psy1, psy2, pds, zds1 and zds2 genes were expressed in both conditions; however, only pds and zds2 expressions were induced in dark grown roots $(\mathrm{Rd})$ relative to the segment of root that was exposed to light (R1, Fig 4A and B). On the other hand, the relative abundance of $\mathrm{zds} 1$ was higher in roots exposed to light (Rl) than in the 12-week-old normal modified root (Rd, Fig 4B), while psy1, psy2 and zds2 transcript levels did not change significantly between the two conditions. These results suggest that the expression of pds and zds 1 is regulated by light.

\section{DISCUSSION}

In this study, morphological analysis and qRT-PCR were used to determine the effect of light on root development and carotenogenic gene expression in Daucus carota L, a novel plant model. This plant produces and accumulates carotenoids in leaves that are exposed to light and in the modified root, grown in darkness. No other plant model synthesizes such amounts of carotenoids in an organ that is not exposed to light. All analyzed carotenogenic genes were expressed in leaves and in modified

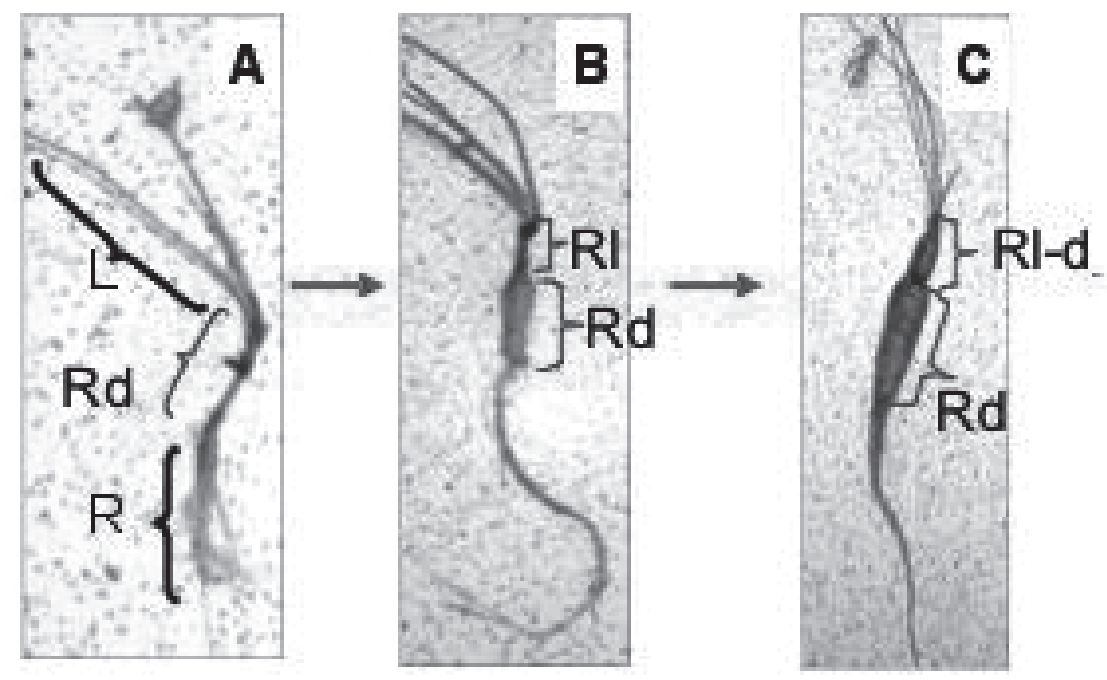

Figure 3: Effect of light on carrot modified root development. A) A 4-week-old D. carota plantlet. L: leaves, R: roots, Rd: Root segment that will develop into a modified root. B) An 8-week-old $D$. carota plantlet. Rl: Light-exposed modified root. Rd: Dark-grown modified root. C) A 12-week-old D. carota plantlet. Rl-d: Modified root exposed to light for 8 weeks, then covered for 4 weeks. Rd: Normal modified root development. Representative plants are shown $(n=10)$. 
roots of carrot, although expression levels differed between these organs, suggesting that different regulatory mechanisms leading to carotenoid accumulation are involved in leaves and roots. To our knowledge, these results demonstrate for the first time that the expression profiles of selected carotenogenic genes are differentially influenced in carrots after dark or light treatments. Clotault et al., (2008), analyzed the transcript accumulation of psy1, psy2, pds, lcyb, zds1, zds2, lcye and zep during modified root development in four carrot varieties. It was show that the expression was correlated to the accumulation of carotenoid pigments. However one of them, Blanche, a white variety, does not accumulate carotenoids, but expresses almost all genes during root development (Clotault et al., 2008). Therefore, the expression of carotenogenic genes does not always lead to a functional carotenogenic enzyme, by the presence of non-functional alleles.
We determined that light induces expression of pds and zds2 in leaves and represses the accumulation of $\mathrm{zds} 1$ transcripts, whilst psy 1 and psy 2 were not affected significantly by light or dark treatments. This suggests that carrot pds1, zds 1 and zds2 genes respond to light and may have light responsive elements (LRE) in their promoters, as was shown for the psy gene promoter of $A$. thaliana, which has LREs, specifically G-box and $G$ box-like elements that respond to light (Welsch et al., 2003; 2007). The results obtained in carrot leaves are in agreement with the relative expression analysis of carotenogenic genes performed in $A$. thaliana and tomato, in which psy and hdr transcripts increased during the transfer of leaves to light after being in darkness (von Lintig et al., 1997; Welsch et al., 2000, Botella-Pavía et al., 2004). However in D. carota leaves, psy2 expression was not affected by light or dark treatments and the induction of psy1 by light was not
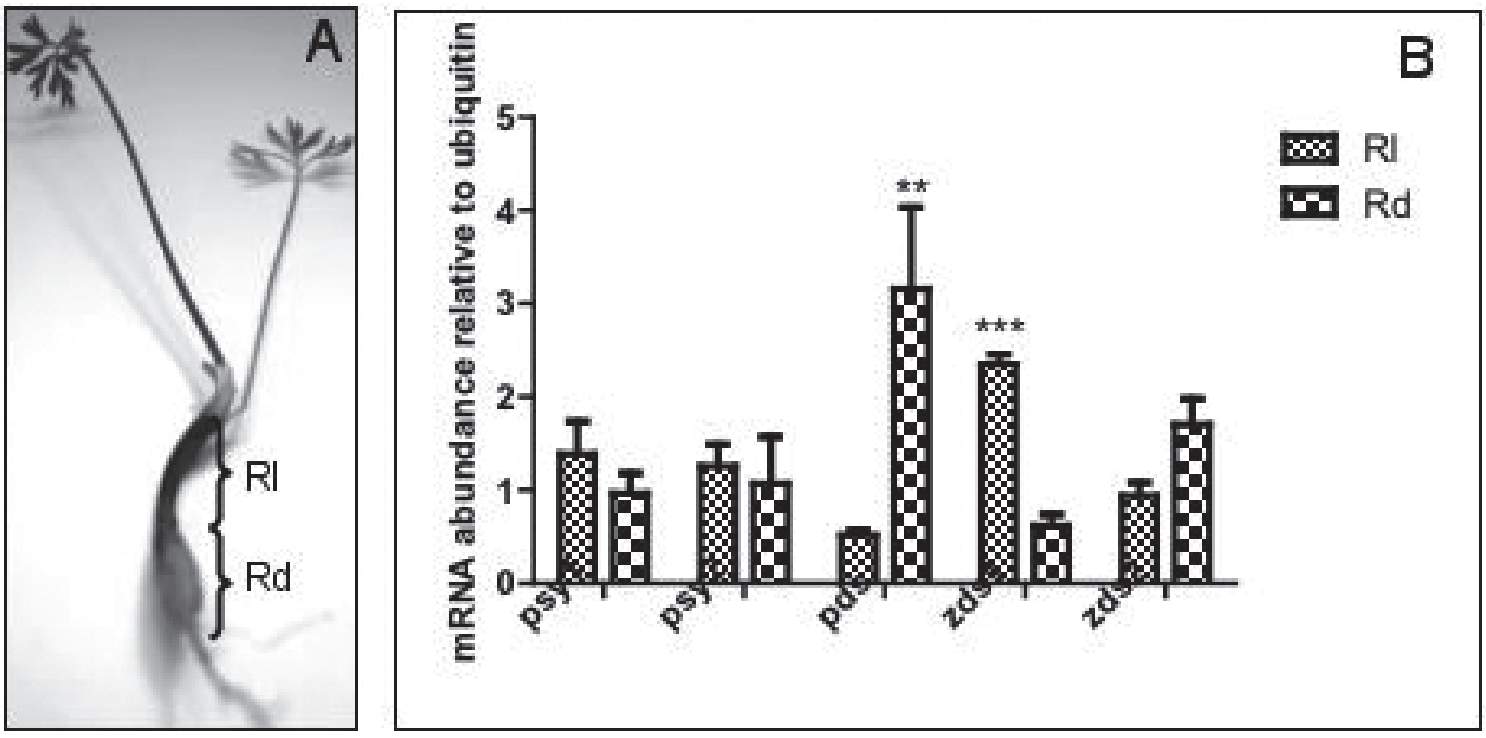

Figure 4: Carotenogenic gene accumulation in roots of D. carota exposed to light or dark conditions A) Morphological development of a 12-week-old carrot plantlet. Light: segment of root that was exposed to light for 4 weeks. Dark: segment of root exposed to continuous darkness. B) Relative transcript accumulation of psy1, psy2, pds, zds1 and zds2 was analyzed by means of real time RT-PCR using root samples indicated in A. Standard deviations (SD) are the result of three independent replicates. Expression data were normalized with ubiquitin and calibrated against the average of each gene's expression for both conditions. Asterisks indicate significant differences in gene expression among treatments. Student t-test, $\mathrm{p}<0.05$. 
statistically significant in relation to the dark treatment (Fig 2). We are currently isolating and characterizing the promoter of pds and zds1 genes to determine whether LREs are present in the promoter sequences.

During darkness, biosynthesis of carotenoids in leaves is stopped due principally to the very low level of expression of carotenogenic genes. In $C$. annum, psy, pds, zds and lcyb, genes are down regulated under these conditions (Simkin et al., 2003) and in A. thaliana the psy and hdr genes are active in darkness only at basal levels (Welsch et al, 2003, BotellaPavía et al., 2004). In carrot, psy1, pds and zds2 genes are also expressed at basal levels in leaves treated for 2 days in the dark.

On the other hand, the accumulation of zds1 mRNA was repressed in the presence of light. Carotenoids are synthesized during light exposure, but it was shown that when light intensity increases from 150 to 280 $\mathrm{mmol} \mathrm{m} \mathrm{m}^{-2} \mathrm{~s}^{-1}$ the rate of photo oxidation is higher than the rate of synthesis and carotenoids are destroyed, reaching a basal level (Simkin et al., 2003). The level of expression of some carotenogenic genes are reduced following prolonged illumination at moderate light intensities (Woitsch and Römer, 2003), as was shown for pds transcript accumulation in tomato seedlings and was referred to as inhibition by final product (lycopene) (Corona et al., 1996; Giuliano et al., 1993). This phenomenon could also explain the behavior of carrot zds1.

In roots, pds and $\mathrm{zds} 1$ were affected significantly by light treatment, whereas zds2 was not, indicating that pds and zds1 genes might have LREs in the promoters. This observation is in agreement with the results obtained in carrot leaves. In $A$. thaliana leaves, it has been shown that light, through PHYA, plays a role in the transcriptional induction of psy in $A$. thaliana (von Lintig et al., 1997), by promoting the binding of the transcription factor HY5 to LREs located in the promoter. It is possible that during modified root development other transcription factors are involved, which are activated by dark conditions and repressed when roots are exposed to light. In this way, pds gene accumulation in modified carrot root could be explained, whereas the expression of zds1 could be associated with a basal level of expression in the modified root through the absence of a specific transcription factor, which is only present in light conditions or could be also associated with repression by final product. Through these results, we can conclude that pds and zds2 genes are important during carotenoid biosynthesis in leaves and in roots, associated directly with normal developmental conditions of each organ.

In contrast to leaves, in fruits, flowers, seeds, root tubers, and reserve roots, carotenoids accumulate in chromoplasts. In these plastids, carotenoids are stored in plastoglobuli, where they are more photostable than in chloroplasts (Merzlyak and Solovchenko, 2002). Therefore, photooxidation does not affect carotenoid content in these organs, even when they are exposed to light. Our results indicate that light has a negative effect on modified carrot root development, possibly because some transcriptional or growth factors are inhibited, although more extensive studies are needed to investigate this phenomenon. Roots exposed to light did not develop normally (Fig.3) and did not synthesize carotenoids compared to roots developed in darkness (data not shown). Therefore, microarray studies could be a helpful tool for the global comparison of genes that are induced or repressed in roots grown in darkness or exposed to light conditions. To date, many specific factors that are implicated in the transcriptional activation of genes regulated by light, such as carotenogenic genes, have been identified by means of microarray analyses. During initial exposure of $A$. thaliana seedlings to light, many transcription factors (HY5, CCA1, LHY, APRR9, APRR5, HYH, SPA1, PKS1) are early over-expressed (Quail, 2007; Tepperman et al., 2001). However, it has yet to be established whether these transcription factors play a role in the induction of carotenogenic genes.

Conventional studies focused on a specific gene or step in the carotenoid pathway combined with new technologies 
permitting an analysis of the entire pathway will be needed to understand the role of light on carotenoid biosynthesis in diverse organisms. Transcriptome analysis will provide insights into regulatory branch points of the pathway, whilst proteomic studies could help to associate the protein/ enzyme component profiles with the carotenoid content in plants. Without doubt, aspects associated with the effect of light on carotenoid biosynthesis regulation will be avenues warranting more intensive research efforts. Research to alter the lightmediated signal transduction machinery would also be an effective approach for modulating chlorophyll and fruit carotenoid content in plants.

\section{ACKNOWLEDGMENTS}

Supported by grant DI I2 05/06-2 from the Universidad de Chile.

\section{BIBLIOGRAPHY}

ALBA R, CORDONNIER-PRATT MM, PRATT LH (2000) Fruit localized phytochromes regulate lycopene accumulation independently of ethylene production in tomato. Plant Physiol 123: 363-370

BARANSKA M, BARANSKI R, SCHULZ H, NOTHNAGEL T (2006) Tissue-specific accumulation of carotenoids in carrot roots. Planta 224(5): 1028-37

BARTLEY G, SCOLNIK P (1993) cDNA cloning expression during fruit development and genome mapping of PSY2, a second tomato gene encoding phytoene synthase. J Biol Chem 268: 25718-25721

BARTLEY G, SCOLNIK P (1995). Plant carotenoids: pigments for photoprotection, visual attraction and human health. Plant Cell 7: 1032

BJERKENG B (2000) Carotenoid pigmentation in salmonid fishes- recent progress. En Cruz-Suarez, LE., RicqueMarie, D., Tapia-Salazar, M., Olvera-Novoa, MA. y Civera-Cereceda, R. (Eds). Avances en Nutrición Acuícola V. Memorias del V Simposium Internacional de Nutrición Acuícola. 19-22 Nov. México

BOTELLA-PAVÍA P, BESUMBES O, PHILLIPS M, CARRETERO-PAULET L, BORONAT A, RODRÍGUEZ-CONCEPCIÓN M (2004) Regulation of carotenoid biosynthesis in plants: evidence for a key role of hydroxymethylbutenyl diphosphate reductase in controlling the supply of plastidial isoprenoid precursors. Plant Cell 40: 188-199

BRAMLEY P (2002) Regulation of carotenoid formation during tomato fruit ripening and development. J Exp Bot 53(377): 2107-2113

BRIGGS W, OLNEY M (2001) Photoreceptors in plant photomorphogenesis to date. Five phytochromes, two Cryptochromes, one phototropin, and one superchrom. Plant Physiol 125: 85-88
BRITTON G (1995) Regulation of carotenoid formation during tomato fruit ripening and development. J Exp Bot 53(377): 2107-2113

BRITTON G, LLAAEN-JEMSEN S, PFANDER H (1998) Carotenoids, biosynthesis and metabolism. Birkhauser, Verlag, Basel, Switzerland Vol 3

CLOTAULT J, PELTIER P, BERRUYER R, THOMAS M, BRIARD M, GEOFFRIAU E. (2008) Expression of carotenoid biosynthesis genes during carrot root development. J Exp Bot Published on line on August 29,2008

CORONA V, ARACRI B, KOSTURKOVA G, BARTLEY GE, PITTO L, GIORGETTI L, SCOLNIK PA, AND GIULIANO G (1996) Regulation of carotenoid biosynthesis gene promoter during plant development. Plant J 9(4): 505-512

CROZIER A, KAMIYA Y, BISHOP G, YOLOTA T (2000) Biosynthesis of hormone and elicitor molecules. Biochemistry and Molecular Biology of Plants. Buchanan B, Gruisemm W, Jones R. Eds. American Society of Plant Physiologist. Cap 17: 865-872

CUNNINGHAM FX, POGSON B, SUN ZR, MCDONALD KA, DELLAPENA D, GANTT E (1996) Functional analysis of the $b$ and e lycopene cyclase enzymes of Arabidopsis reveals a mechanism for control of cyclic carotenoid formation. Plant Cell 8: 1613-1626

CUNNINGHAM FX JR, GANTT E (1998) Genes and enzymes of carotenoid biosynthesis in plants. Annu Rev Plant Physiol Plant Mol Biol 49: 557-583

CUNNINGHAM FX JR (2002) Regulation of carotenoid synthesis and accumulation in plants. Pure Appl Chem 74(8): 1409-1417

DALL'OSTO L, LICO C, ALRIC J, GIULIANO G, HAVAUX M, BASSI R (2006) Lutein is needed for efficient chlorophyll triplet quenching in the major LHCII antenna complex of higher plants and effective protoprotection in vivo under strong light. BMC Plant Biol. 6(1): 32

ESTERBAUER H, GEBIKI J, PUHL H, JURGENS G (1992) The role of lipid peroxidation and antioxidants in oxidative modification of LDL. Free Radic Biol Med 13(4): 341-391

FRANKLIN K, LARNER V, WHITELAM G (2005) The signal transducing photoreceptor of plants. Int $\mathrm{J}$ Dev Biol 49: 653-664

FRASER PD, TRUESDALE MR, BIRD CR, SCHUCH W, BRAMLEY PM (1994) Carotenoid biosynthesis during tomato fruit development. Plant Physiol 105: 405-413

FRASER P, KIANO J, TRUESDALE M, SCHUCH W, BRAMLEY P (1999) Phytoene synthase-2 enzyme activity in tomato does not contribute to carotenoid synthesis in ripening fruit. Plant Mol Biol 40: 687-698

FRASER P, BRAMLEY P. 2004. The biosynthesis and nutritional uses of carotenoids. Prog Lipid Res 43: 228265

GIULIANO G. 1993. Regulation of carotenoid biosynthesis gene promoter during plant development. Plant J 9(4): 505-512

GIORIO G, STIGLIANI AL, D'AMBROSIO C. (2008) Phytoene synthase genes in tomato (Solanum lycopersicum L.) - new data on the structures, the deduced amino acid sequences and the expression patterns. FEBS J 275: 527-535

GIOVANNONI JJ (2004) Genetic regulation of fruit development and ripening. Plant Cell 16: S170-S180

GIULIANO G, BARTLEY GE, SCOLNIK PA (1993) Regulation of carotenoid biosynthesis during tomato development. Plant Cell 5: 379-387

GROTEWOLD E. (2006) The genetics and biochemistry of floral pigments. Annu Rev Plant Biol 57: 761-780 
HIRSCHBERG J, COHEN M, HARKER M, LOTA T, MANN V, PECKER I (1997) Molecular genetics of carotenoid biosynthesis pathway in plants and algae. Pure Appl Chem 69: 2145-2150

HIRSCHBERG J (2001) Carotenoids biosynthesis in flowering plants. Curr Opin Plant Biol 4: 210-218

HOLE CC (1996) Photoassimilate distribution in plants and crops. Marsel Dekker, New York. pp. 671-690

HOWITT CA, POGSON BJ (2006) Carotenoid accumulation and function in seeds and non-green tissues. Plant Cell Environ 29: 435-445

ISAACSON T, RONEN G, ZAMIR D, HIRSCHBERG J (2002) Cloning of tangerine from tomato reveals a carotenoid isomerase essential for the production of carotene and xanthophylls in plants. Plant Cell 14: $333-$ 342

ISAACSON T, OHAD I, BEYER P, HIRSCHBERG J (2004) Analysis in vitro of the enzyme CRTISO establishes a poly-cis-carotenoid pathway in plants. Plant Physiol 136: 4246-4255

JUST BJ. SANTOS CAF, FONSECA MEN, BOITEX LS, OLIOZIA BB, SIMON PW. (2007) Carotenoids biosynthesis structural genes in carrot (Daucus carota): isolation, sequence-characterization, single nucleotide polymorphism (SNP) markers and genome mapping. Theor App Genet 114: 693-704

KATO M, IKOMA Y, MATSUMOTO H, SUGIURA M, HYODO H, YANO M (2004) Accumulation of carotenoids and expression of carotenoid biosynthetic genes during maturation in citrus fruit. Plant Physiol 134: 824-837

KITA M, KATO M, BAN Y, HONDA C, YAEGAKI H, IKOMA Y, MORIGUCHI T (2007) Carotenoid accumulation in japanese apricot (Prunus mume Siebold \& Zucc.): Molecular analysis of carotenogenic gene expression and ethylene regulation. J Agricult Food Chem, online article 31/3/07

KISHIMOTO S, OHMIYA A. (2006). Regulation of carotenoid biosynthesis in petals and leaves of chrysanthemum (Chrysanthemum morifolium). Physiol Plant 128, 436-447

KLAUI H, BAUERNFEIND JC (1981) Carotenoids as food color. Bauernfeind, JC. ed 1981. Carotenoids as colorants and vitamin A precursors. London: Academic

KRINSKY N, WANG X-D, TANG T, RUSSELL R (1994) Cleavage of $b$-carotene to retinoid. In retinoids: Basic Science and Clinical Applications, Ed. MA Livrea, G Vidali pp21-28. Base: Birkhaeuser

LICHTENTHALER HK, SCHWENDER J, DISH A, ROHMER M (1997) Biosynthesis of isoprenoids in higher plant chloroplasts proceeds via mevalonateindependent pathway. FEBS lett 400: 271-274

LICHTENTHALER HK (1999) The 1-deoxy-D-xylulose-5phosphate pathway of isoprenoid biosynthesis in plants. Annu Rev Plant Physiol Plant Mol Biol 50: $47-$ 65

LODATO P, ALCAÍNO J, BARAHONA S, RETAMALES P, JIMÉNEZ A, CIFUENTES V (2004) Study of the expression of carotenoid biosynthesis genes in wildtype and deregulates strains of Xanthophylomyces dendrorhous (ex.: Phaffia rodhozyma). Biol Res 37(1): 83-93

LOIS L, RODRÍGUEZ C, GALLEGO F, CAMPOS N, BORONAT A (2000) Carotenoid biosynthesis during tomato fruit development: regulatory role of 1-deoxiD-xylulose 5-phosphate synthase. Plant J 22: 503-513

MAYNE, S (1996) $\beta$-carotene, carotenoids and disease prevention in humans. FASEB J 10: 690-701

MAZZELLA MA, ALCONADA TM, CASAL JJ (1997) Dual effect of phytochrome A on hypocotyl growth under continuous red light. Plant Cell Environ 20: 261267

MERZLYAK MN, SOLOVCHENKO AE (2002) Photostability of pigments in ripening apple fruit: a possible photoprotective role of carotenoids during plant senescence. Plant Sci 163: 881-888

MORDI RC (1993) Carotenoids: Functions and degradation. Chem Ind 3: 79-83

NAIK PS, CHANEMOUGASOUNDHARAM A, KHURANA SMP, Y KALLO G (2003) Genetic manipulation of carotenoid pathway in higher plants. Curr Sci 85(10): 1423-1430

NAGY F, SCHAFER E (2002) Phytochromes control photomorphogenesis by differentially regulated, interacting signaling pathways in higher plants. Annu Rev Plant Biol 53: 329-355

NESTERENKO S, SINK KC (2003) Carotenoid profiles of potato breeding lines and selected cultivars. Hortscience 38, 1173-1177

PANFILI G, FRATIANNI A, IRANO M (2004) Improved normal-phase-high-performance liquid chromatography procedure for the determination of carotenoids in cereals. J Agric Food Chem 52: 6373-6377

PARK H, KREUNEN SS, CUTTRISS AJ, DELLAPENNA D, POGSON BJ (2002) Identification of the carotenoid isomerase provides insight into carotenoid biosynthesis, prolamellar body formation, and photomorphogenesis. Plant Cell 14: 321-332

PECKER I, GUBBAY R, CUNNINGHAM JR FX, HIRSHBERG J (1996) Cloning and characterization of the cDNA for lycopene $\beta$ cyclase from tomato reveal a decrease in its expression during tomato ripening. Plant Mol Biol 30: 806-819

PHILLIPS LA, BARRY C, GIOVANNONI J. Signal transduction systems regulating fruit ripening. Trends Plant Sci 9: 331-338

PFAFFL MW. (2001) a new mathematical model for relative quantification in real-time RT-PCR. Nucl. Acids Res. 29, e45

QUAIL PH (2007) Phytochrome-regulated gene expression. J Integr Plant Biol 49: 11-20

RAI M, DATTA K, PARKHI V, TAN J, OLIVA N, CHAWLA HS, DATTA SK. (2007) Variable T-DNA linkage configuration affects inheritance of carotenegenic transgenes and carotenoid accumulation in transgenic indica rice. Plant Cell Rep 26: 1221-1231

RAO AV, RAO LG (2007) carotenoids and human health. Pharmacological Res. 55: 207-216

ROHMER M (1999) The discovery of a mevalonate independent pathway for isoprenoid biosynthesis in bacteria, algae and higher plants. Nat Prod Rep 16: 565-574

RÖMER S, FRASER PD (2005) Recent advances in carotenoid biosynthesis, regulation and manipulation. Planta 221: 305-308

RONEN G, COHEN M, ZAMIR D, HIRSHBERG J (1999) Regulation of carotenoid biosynthesis during tomato fruit development: expression of gene for lycopene epsilon cyclase is down regulated during ripening and is elevated in the mutant delta. Plant J 17: 341-351

SCHEPENS I, DUEK P, FANKHAUSER C (2004) Phytochrome-mediated light signaling in Arabidopsis. Curr Opin Plant Biol 7: 564-569

SCHOFIELD A, PALIYATH G (2005) Modulation of carotenoid biosynthesis during tomato fruit ripening through phytochrome regulation of phytoene synthase activity. Plant Physiol Biochem 43: 1052-1060

SCHWENDER J, SEEMANN M, LICHTENTHALER HT, ROHMER M (1996) Biosynthesis of isoprenoids (carotenoids, sterols, prenyl side-chains of chlorophylls 
and plastoquinone) via a novel pyruvate/ glcyeraldehydes 3-phosphate non-mevalonate pathway in the green alga Scenedesmus obliquus. Biochem J 316: $73-80$

SHANKER V, BHALLA R, LUTHRA R (2003) An overview of the non-mevalonate pathway for terpenoid biosynthesis in plants. J Biosci 28: 637-646

SIMON PW, WOLFF XY (1987) Carotenes in typical and dark orange carrots. J Agric Food Chem 35: 1017-1022

SIMKIN AJ, ZHU C, KUNTZ M, SANDMANN G (2003) Light-dark regulation of carotenoid biosynthesis en pepper (Capsicum annuum) leaves. J Plant Physiol 160: 439-443

SNODERLY, D (1995) Evidence for protection against age-related macular degeneration by carotenoids and antioxidant vitamins. Am J Clin Nutr 62: 1448S-1461S

SUSLOW TV, WU J, PEISER G (1999) Characterization of Carotenoid Composition of Carrots Affected by "Light Root Syndrome" Perishables Handling Quarterly Issue No. 100, 11-12

TAKANO H, OBITSU S, BEPPU T, UEDA K (2005) Light-induced carotenogenesis in Streptomyces coelicolor A 3(2): Identification of extracytoplasmic function sigma factor that directs photodependent transcription of the carotenoid biosynthesis gene cluster. J Bacteriol 187: 1825-1832

TELFER A (2005) Too much light? How -carotene protects the photosystem II reaction centre. Photochem Photobiol Sci 4: 950-956

TEPPERMAN JM, ZHU T, CHANG HS, WANG $X$, QUAIL PH (2001) Multiple transcription-factor genes are early targets of phytochrome A signaling. Proc Natl Acad Sci USA 98: 9437-42

VISHNEVETSKY M, OVADIS M, VAINSTEIN A. (1999) Carotenoid sequestration in plants: the role of carotenoid associated proteins. Trends Plant Sci 4: 232-235

VON LINTIG J, WELSCH R, BONK M, GIULIANO G, BATSCHAUER A, KLEINIG H (1997) Lightdependent regulation of carotenoid biosynthesis occurs at the level of phytoene synthase expression and is mediated by phytochrome in Sinapsis alba and Arabidopsis thaliana seedlings. Plant J 12: 625-634

WELSCH R, BEYER P, HUGUENEY P, KLEINIG H, VON LINTIG J (2000) Regulation and activation of phytoene synthase, a key enzyme in carotenoid biosynthesis, during photomorphogenesis. Planta 211: 846-854

WELSCH R, MEDINA J, GIULIANO G, BEYER P, VON LINTIG J (2003) Structural and functional characterization of the phytoene synthase promoter from Arabidopsis thaliana. Planta 216: 523-534

WOITSCH S, RÖMER S (2003) Expression of xanthophyll biosynthetic genes during light-dependent chloroplast differentiation. Plant Physiol 132: 1508-1517

YADAV V, KUNDU S, CHATTOPADHYAY D, NEGI P, WEI N, DENG XW, CHATTOPADHYAY S (2002) Light regulated modulation of Z-box containing promoters by photoreceptors and downstream regulatory components, COP1 and HY5, in Arabidopsis. Plant J. 31: 741-753

ZHU C, YAMAMURA S, KOIWA H, NISHIHARA M, SANDMANN G (2002) cDNA cloning and expression of carotenogenic genes during flower development in Gentiana lutea. Plant Mol Biol 48(3): 277-285

ZHU C, YAMAMURA S, NISHIHARA M, KOIWA $\mathrm{H}$, SANDMANN G (2003) cDNAs for the synthesis of cyclic carotenoids in petals of Gentiana lutea and their regulation during flower development. Biochem Biophys Acta 1625: 305-308 